\title{
Bel ağrısı tanı ve tedavisinde kırmızı ve mavi bayraklar
}

\author{
Red and blue flags in the diagnosis and treatment of low back pain
}

\author{
H. Yener Erken
}

Özel Şişli Kolan Hastanesi Ortopedi ve Travmatoloji Kliniği, Okmeydanı, İstanbul

Bel ağrısı çeken çoğu hasta basit bir tedaviyle düzelmesine rağmen, bel ağrılı hastada doğru bir değerlendirme, altta yatan ciddi patolojilerin ortaya konulabilmesi için çok önemlidir. Bel ağrısında kırmızı bayrak olarak adlandırılan neoplastik sorunlar, enfeksiyon, kauda ekina sendromu ve kırık gibi bulgular, ciddi patolojileri düşündüren semptomlardır. Bu semptomların varlığı, hastanın omurga cerrahına yönlendirilmesini ve ayrıntılı bir incelemeyi gerektirir.

Psikososyal faktörlerin de bel ağrısına bağlı uzun dönem sakatlık ve geç işe dönüşte önemli bir rolünün olduğu bildirilmektedir. Hekimin psikososyal faktörleri değerlendirmesine yardımcı olmak amacıyla, kırmızı bayrakların yanı sıra değişik renkte bayraklardan oluşan bir tanımlama sistemi oluşturulmuştur. Bu sistemde, mavi bayrak işle ilgili algıları bel ağrısının iyileşmesini etkileyen hastayı tanımlar. Birçok mavi bayrak bulgusu tanımlanmış olup, literatürdeki derlemeler "iyileşme" nin en iyi prognostik göstergesinin, işe dönüş beklentisi olduğunu göstermektedir.

Anahtar sözcükler: bel ağrısı; kırmızı bayraklar; mavi bayraklar
Although most patients suffering from lower back pain find relief after simple treatments, proper diagnosis is crucial in determining more serious underlying pathologies. The symptoms of lower back pain considered as "red-flag" symptoms, including neoplastic problems, infection, cauda equina syndrome and vertebral fractures, are often indicators of more serious pathologies. The presence of these symptoms require the patient to be directed to a spine surgeon for a more in-depth evaluation.

It is reported that psychosocial factors also play an important role in long term disability and a delay in return-towork due to lower back pain. A color-coded "flag" system in addition to the "red-flag" list of symptoms has been developed to assist clinicians in evaluating psychosocial factors. According to this system, a "blue flag" defines a patient whose work-related perceptions affect the recovery of his lower back. While many "blue flag" symptoms have been identified, literature suggests that the best prognostic indicator of recovery is expectation to return to work.

Key words: low back pain; red flags; blue flags
B el ağrısı önemli, sosyoekonomik sonuçları olan küresel bir sorundur ve kas-iskelet sistemi ağrılarında ön sırada yer alır. Çoğu kişi hayatının bir döneminde bel ağrısı yaşamaktadır. Olguların çoğunun spesifik bir tanısı olmayıp, spesifik olmayan bel ağrısı olarak isimlendirilmektedir. ${ }^{[1]}$ Birçok hasta basit bir tedaviyle düzelmesine rağmen, doğru bir değerlendirme, altta yatan ciddi bir patolojinin ortaya konulabilmesi için çok önemlidir. Bel ağrısının birçok nedeni olup, en sık olanı mekanik bel ağrısıdır. Bu durumdan en çok disk dejenerasyonu ve ligamentöz yapılardaki burkulma ve gerilmeler suçlanır. Bunun dışındakiler ise; nörojenik kaynaklı bel ağrısı, mekanik olmayan sorunlar ve diğer nedenler olarak sıralanmaktadır (Tablo 1). ${ }^{[2]}$
Bel ağrısında kırmızı bayrak olarak adlandırılan bulgular; neoplastik sorunlar, enfeksiyon, kauda ekina sendromu ve kırık gibi ciddi patolojileri düşündüren semptomlardır. Bu semptomların varlığı, hastanın omurga cerrahına yönlendirilmesini ve ayrıntılı bir inceleme gerektirir. Bu durumlar bel ağıssı nedenleri arasında oldukça küçük bir grubu oluşturmakla beraber, tanısı konulamadığı zaman morbidite ve mortalite oranları çok yüksek olabilir. O nedenle, bel ağrısı ile başvuran hastalarda kırmızı bayraklar iyi analiz edilip, gerekirse hastaların ileri tetkiklerinin yapılması oldukça önemlidir.

Literatürdeki çalışmalar, bel ağrısı kaynaklı uzun dönem sakatlık ve geç işe dönüşte psikososyal faktörlerin

- İletişim adresi: Doç. Dr. H. Yener Erken, Cumhuriyet Mahallesi, 2255 Sokak No: 3, Gebze, Kocaeli

Tel: 0216 - 5471146 e-posta: yenererken@yahoo.com

- Geliş tarihi: 17 Ağustos 2015 Kabul tarihi: 17 Ağustos 2015 
Tablo 1. Bel ağrısı nedenleri

\begin{tabular}{|c|c|}
\hline Mekanik nedenler (\%80-90) & $\begin{array}{l}\text { - Nedeni bilinmeyen nedenler (Kas ve ligamentöz kaynaklı) } \\
\text { - Disk dejenerasyonu } \\
\text { - Faset eklem kaynaklı } \\
\text { - Vertebra kırıkları } \\
\text { - Spondilolizis } \\
\text { - Instabilite } \\
\text { - Spinal deformiteler } \\
\text { - Başarısız bel cerrahisi sendromu sonrası }\end{array}$ \\
\hline Nörojenik nedenler (\%5-15) & $\begin{array}{l}\text { - Lomber disk hernisi } \\
\text { - Lomber spinal stenoz } \\
\text { - Sinir köküne osteofit basısı } \\
\text { - Annüler yırtıkla oluşan kimyasal sinir kökü iritasyonu } \\
\text { - Başarısız bel cerrahisi sendromu sonrası } \\
\text { - Enfeksiyon (Herpes Zoster) }\end{array}$ \\
\hline Mekanik olmayan patolojiler (\%1-2) & $\begin{array}{l}\text { - Malignite (Primer veya metastatik tümörler) } \\
\text { - Enfeksiyon (Spondilodiskit, osteomiyelit, abse) } \\
\text { - Inflamatuvar spondiloartropatiler } \\
\text { - Paget hastalığı }\end{array}$ \\
\hline Diğer nedenler (\%2-4) & $\begin{array}{l}\text { - Fibromiyalji } \\
\text { - Konnektif doku hastalıkları } \\
\text { - Somatoform bozukluklar } \\
\text { - Abdominal aort anevrizması } \\
\text { - Gastrointestinal nedenler } \\
\text { - Pelvik nedenler } \\
\text { - Retroperitoneal nedenler }\end{array}$ \\
\hline
\end{tabular}

de önemli bir rolünün olduğunu belirtmektedir. ${ }^{[3,4]} \mathrm{Bu}$ nedenle, bel ağrısının tedavisinde tanımlanmış uluslararası kılavuzlar, klinik değerlendirme sırasında psikososyal faktörlerin de tedavi sürecinde değerlendirilmesini önermektedir. ${ }^{[5,6]}$ Klinisyenin psikososyal faktörleri değerlendirmesine yardımcı olmak amacıyla, kırmızı bayrakların yanı sıra, değişik renkte bayraklardan oluşan bir tanımlama sistemi oluşturulmuştur (Tablo 2). ${ }^{[7,8]}$ Bu sistemde, mavi bayraklar hastanın bel ağrısının iyileşmesini etkileyebilen işle ilgili algıları olarak tanımlanmıştır. ${ }^{[9]}$ Mavi bayraklara örnek olarak; "işe dönmeyle ilgili negatif beklentiler", "iş tatminsizliği", "iş yerinde stres", "işin sağlığına zarar vereceğini düşünme”, "yeniden yaralanma korkusu", "fizik güç gerektiren iş konusundaki algılar ve endişeler", "işyerindeki amir ve çalışma arkadaşlarıyla kötü ilişkiler" olarak sayılabilir. Ancak, mavi bayrak bulgularının hepsinin hastanın tedaviye yanıtındaki rolleri aynı değildir. Kanıt düzeyi en yüksek olan bulgu, "hastanın iyileşme ve işe dönme konusundaki beklentisi"dir. Sistemik analizler, çalışanın iyileşme veya işe dönebilme konusundaki beklentisinin az olmasının prognozda özellikle önemli olduğunu göstermiştir. ${ }^{[10]}$

\section{KIRMIZI BAYRAKLAR}

Bel ağrılı bir hastanın doğru ve eksiksiz bir anamnez ve fizik muayene ile değerlendirilmesi son derece önemlidir. Kırmızı bayrak olarak adlandırılan bulgular, genelde daha sık görülen ve daha benign karakterdeki bel ağrılarının, acil tanı ve tedavi gerektiren daha ciddi durumlardan ayrılmasına yardımcı olur. Bel ağrısında kırmızı bayrak bulguları literatürde tanımlanmıştır (Tablo 3). ${ }^{[2,11]}$

Klasik kırmızı bayrak bulguları, klinik gözlemler ve geriye dönük analizler yardımı ile oluşturulmuştur. Bu nedenle, literatürde hangi bulguların kırmızı bayrak bulgusu olarak tanımlanacağı konusunda da çelişkiler mevcuttur. Uzun süreli bel ağrılarının tedavisinde, fizyoterapi klinik kılavuzlarında subjektif öyküde 119 bulgu, objektif öyküde ise 44 bulgu kırmızı bayrak olarak tanımlanmıştır. ${ }^{[12]}$ Bu kılavuzlarda, kırmızı bayrak bulguları arasında da çeşitlilik olmakla beraber, bunların hiçbiri hakkında \%100 fikir birliğine varılamamıştır. ${ }^{[12]}$ Roberts ve arkadaşlarının yaptıkları derlemede ise, Tablo 3'te belirtilen 11 adet klasik kırmızı bayrak bulgusu üzerinde \%50'den daha fazla fikir birliği oluşmuştur. ${ }^{[13]}$ Klinik kılavuzlardaki bu çeşitliliklerden dolayı, kırmızı bayrakların klinik kullanımlarında da birçok fark ortaya çıkmıştır. Kırmızı bayrakları tek tek kullanmaktan ziyade, hiyerarşik bir sıra içinde kullanmanın daha iyi bir yol gösterici olduğu konusunda da bir fikir birliği mevcuttur. ${ }^{[11]}$ Literatürde altın standart olarak tanımlanmış tek bir kırmızı bayrak listesi olmamakla beraber, bu konuda birçok çalışması olan 
Tablo 2. Bayrak tanımlama sisteminin özeti

\begin{tabular}{|c|c|c|}
\hline Bayrak & Doğası & Örnek \\
\hline Kırmızı & Ciddi patoloji bulguları & - Kauda ekina sendromu, kırık, tümör \\
\hline Turuncu & Psikiyatrik semptomlar & - Klinik depresyon, kişilik problemleri \\
\hline \multirow[t]{3}{*}{ Sarı } & İnançlar, değerler ve yargılar & $\begin{array}{l}\text { - Ağrı hakkında yanlış inançlar: Bulguların kontrol edilemeyeceği veya kötüleşmeye } \\
\text { eğilimli olduğuna inanma }\end{array}$ \\
\hline & Duygusal cevaplar & $\begin{array}{l}\text { - Mental hastalık tanı kriterlerine uymayan üzüntüler. } \\
\text { - Endişe, korku, kaygı }\end{array}$ \\
\hline & $\begin{array}{l}\text { Ağrı davranışı (Ağrı kopyalama } \\
\text { davranışlarını da içerir) }\end{array}$ & $\begin{array}{l}\text { - Ağrı ve muhtemel yeni yaralanma korkusu nedeniyle aktivitelerden kaçınma } \\
\text { - Pasif tedavi modalitelerine aşırı güvenme (sıcak uygulaması, soğuk uygulaması, } \\
\text { analjezikler vb.) }\end{array}$ \\
\hline Mavi & $\begin{array}{l}\text { Sağlık ve iş arasındaki ilişki } \\
\text { hakkındaki algılar }\end{array}$ & $\begin{array}{l}\text { - İşin ağır olduğu ve muhtemelen yeni bir yaralanmaya yol açacağına inanma } \\
\text { - İşyerindeki amirlerinin ve çalışma arkadaşlarının yeterince destekleyici olmadığına } \\
\text { inanma }\end{array}$ \\
\hline Siyah & Sistemsel veya özel engeller & $\begin{array}{l}\text { - İşe dönüşe engel olan kanuni seçenekler } \\
\text { - Yaralanma ve tazminat talepleri hakkında sigorta ile anlaşmazlık } \\
\text { - Aşırı endişeli aile veya sağlık ekibi } \\
\text { - Ağır iş yükü ve görevi modifikasyonunda çok kısıtlı seçenek olması }\end{array}$ \\
\hline
\end{tabular}

Tablo 3. Klasik ve yeni tanımlanmış kırmızı bayraklar

\begin{tabular}{ll}
\hline Klasik kırmızı bayrak bulguları & Yeni kırmızı bayrak bulguları \\
\hline Açıklanamayan kilo kaybı & Şerit tarzında gövde ağrısı \\
Kanser öyküsü & Belirsiz non-spesifik alt ekstremite semptomları \\
Gece ağrısı & Azalmış mobilite \\
50 yaşın üzerinde olma & \\
Travma & \\
Ateş & \\
Eyer şeklinde anestezi & \\
Idrar yapmakta zorluk & \\
Intravenöz ilaç kullanımı & \\
ilerleyici nörolojik defisit & \\
Sistemik kortikosteroid kullanımı &
\end{tabular}

Greenhalgh ve Selfe, "şerit tarzında gövde ağrısı, belirsiz non-spesifik alt ekstremite semptomları ve azalmış mobilite" bulgularını da geleneksel kırmızı bayrak bulgularına ekleyip yeni bir liste tanımlamışlardır. Yazarlar, bu yeni bulgular tek başlarına çok anlamlı olmasa bile, klasik kırmızı bayrak bulguları ile birlikte değerlendirildiğinde ciddi spinal patolojiyi ortaya koymada oldukça kullanışlı olduğunu bildirmişlerdir (Tablo 4). ${ }^{[11]}$ Nörolojik kayıp her zaman bir kırmızı bayrak bulgusu olmamakla beraber, nörolojik kaybın ilerleyici olması durumunda kırmızı bayrak bulgusundan söz etmek daha doğrudur. Ek olarak, ciddi spinal patolojilerin erken dönem bulgularını taklit eden bazı hastalıklar/durumlar da akılda tutulmalıdır. Bu patolojilerin verdiği bulgular, hekimler tarafından yanlış bir kırmızı bayrak bulgusu olarak değerlendirilebilmektedir. Bu patolojiler Tablo 4'te belirtilmiştir. ${ }^{[11]}$

Kırmızı bayrak bulgularının her birinin veya kombinasyonlarının prognostik gücünü gösteren sınırlı sayıda
Tablo 4. Ciddi spinal patoloji bulguları verebilen durumlar

\begin{tabular}{l}
\hline Üst motor nöron hastalığı \\
Multipl skleroz \\
Diabet \\
Alkolizm \\
Servikal miyelopati \\
Periferik nöropati \\
Kardiyovasküler hastalıklar sonucu oluşan ve bacaklarda ağırlığa \\
yol açan alt ekstremite ödemi \\
Spinal stenoz \\
Sinir kökü basısı
\end{tabular}

klinik çalışma mevcuttur. Henschke ve arkadaşları, ${ }^{[14]}$ yapmış oldukları çalışmada bazı bulguların diğerlerinden daha değerli olduğu ve kırmızı bayrakların geneline bakıldığında, ciddi spinal patolojileri ortaya koymada yetersiz kalabildiğini belirtmişlerdir. Bu çalışmada, en sık tespit edilen ciddi spinal patolojinin vertebral kırık olduğu belirtilmiştir. Uzun süre kortikosteroid 
Tablo 5. Bel ağrısında kırmızı bayrakların etiyolojik dağılımı

\begin{tabular}{|c|c|c|}
\hline Muhtemel Etiyoloji & Özgeçmiş bulguları & Fizik muayene bulguları \\
\hline Malignite & $\begin{array}{l}\text { Kuvvetli bulgular: } \\
\text { • Kemiğe metastaz yapmış olan kanser öyküsü } \\
\text { Orta derecede bulgular: } \\
\text { • Açıklanamayan kilo kaybı } \\
\text { Zayıf bulgular: } \\
\text { • Kanser öyküsü } \\
\text { • İstirahatle artan veya azalmayan ağrı }\end{array}$ & $\begin{array}{l}\text { Zayıf bulgular: } \\
\text { - Vertebralarda hassasiyet } \\
\text { - Spinal ROM'da kısıtlılık }\end{array}$ \\
\hline Kauda ekina sendromu & $\begin{array}{l}\text { Kuvvetli bulgular: } \\
\text { - Mesane veya barsak inkontinansı } \\
\text { - Üriner retansiyon } \\
\text { - Illerleyici motor veya duyusal kayıp }\end{array}$ & $\begin{array}{l}\text { Kuvvetli bulgular: } \\
\text { - Majör motor veya duyusal kayıp } \\
\text { - Anal sifinkter tonus kaybı } \\
\text { • Eyer şeklinde anestezi } \\
\text { Zayıf bulgular: } \\
\text { - Spinal ROM'da kısıtlılık }\end{array}$ \\
\hline Kırık & $\begin{array}{l}\text { Kuvvetli bulgular: } \\
\text { • Yaş ile ilişkili travma* } \\
\text { Orta derecede bulgular: } \\
\text { • Uzun süre steroid kullanımı } \\
\text { Zayıf bulgular: } \\
\text { • Hastanın } 70 \text { yaşından büyük olması } \\
\text { • Osteoporoz öyküsü }\end{array}$ & $\begin{array}{l}\text { Zayıf bulgular: } \\
\text { - Vertebral hassasiyet } \\
\text { - Spinal ROM'da kısıtılık }\end{array}$ \\
\hline Enfeksiyon & $\begin{array}{l}\text { Kuvvetli bulgular: } \\
\text { • Geçmiş yılda geçirilmiş lomber spinal cerrahi ve ciddi ağrı } \\
\text { Orta derece bulgular: } \\
\text { • Intravenöz ilaç kullanımı } \\
\text { • Immmünosupresyon } \\
\text { • Eski geçirilmiş lomber spinal cerrahi ve ciddi ağrı } \\
\text { Zayıf bulgular: } \\
\text { • İstirahatle artan veya azalmayan ağrı }\end{array}$ & $\begin{array}{l}\text { Kuvvetli bulgular: } \\
\text { - Ateş } \\
\text { - Üriner sistem enfeksiyonu } \\
\text { - Spinal bölgede açık yara } \\
\text { Zayıf bulgular: } \\
\text { - Vertebral hassasiyet } \\
\text { - Spinal ROM'da kısıtlılık }\end{array}$ \\
\hline
\end{tabular}

*Genç hastaya yüksekten düşme veya motorlu taşıt kazası gibi majör bir travma, osteoporozu olan veya muhtemelen osteoporozu olan bir hastada minör bir düşme veya ağır kaldırma vb.

kullanımının, hastanın 70 yaşından yaşlı olmasının ve belirgin travma öyküsünün olmasının (gençlerde majör, yaşlılarda minör travma) ciddi spinal patolojiyi ortaya koymada en kullanışlı kırmızı bayrak bulguları olduğu da bildirilmiştir. ${ }^{[14]}$

Hastanın travma öyküsü, yaş grubuna ve hastaya göre değerlendirilmelidir. Osteoporotik olan bir hastada; ağır yük kaldırmak, öksürmek veya yüksek bir merdivenden inmek gibi minör bir travma sonrası da vertebra kırığı oluşabilmektedir. Bu nedenle, ostoporotik hastalarda belirgin bir travma olmaksızın daha önceki bel ağrılarında artış önemli bir bulguyken, daha genç ve sağlıklı bir hastada, yüksekten düşme veya motorlu araç kazası gibi daha ciddi travmalar dikkate alınmalıdır. Tablo 5, kırmızı bayrak bulgularını muhtemel etiyolojiye göre sınıflandırmaktadır. Bu tabloda yer alan 1-2 adet zayıf veya orta derecede bulgunun varlığı takip gerektirebilirken, herhangi bir kuvvetli bulgunun varlığı daha acil bir incelemeyi gerektirir. ${ }^{[14,15]}$
Hastanın öyküsünde; bel ağrısının tipi, ne zaman başladığı, süresi, şiddeti, yayılımı oldukça önemlidir. Mekanik bel ağrısı; hastanın yatakta hareket etmesi, ayakta durması veya oturması gibi aktivitelerle omurgaya binen yükün artmasıyla oluşur ve dinlenmekle azalır. Genellikle dejeneratif ve travmatik patolojiler ile ortaya çıkmakta olup, istirahat ağrısı ile ayrımı önemlidir. İstirahat ağrısı, istirahatle artan veya azalmayan ağıı olarak tanımlanmakla birlikte, neoplastik veya enfeksiyöz patolojilerin ayırıcı tanısında önemlidir. İstirahat ağrısında hasta, yatakta yatarken de ağrısı vardır ve ağrısız rahat edeceği bir pozisyon bulamaz. Ateş, iştahsızık, kilo kaybı gibi sorunlar akla ilk olarak piyojenik enfeksiyonu getirmekle beraber, omurga tüberkülozunda bu bulgular ortaya her zaman çıkmayabilir. Açıklanamayan kilo kaybı, malignitelerde de sıkça görülen bir bulgudur. ${ }^{[2]}$ Özellikle 50 yaşın üstündeki hastalar malignite açısından araştırılmalıdır. Bazen malignitenin primer tanısı, metastaz sonucu ortaya 
çıkan bel ya da sırt ağrısı sonrası ortaya konulur. Elli yaşın üzerinde, açıklanamayan kilo kaybı olan ve istirahatle geçmeyen ağrısı olan hastalarda, özellikle metastatik omurga tümörü akla gelmelidir. ${ }^{[14]}$

Kırmızı bayrakların varlığında doğru tetkiklerin istenmesi ile ancak doğru tanı konulabilir. ilk olarak yapılacak tetkik direkt grafi olmakla beraber erken dönemde tümör ve enfeksiyon bulgularını göstermeyebilir. Ayrıca osteoporotik kırık varlığında eski ve yeni kırık ayrımını yapamaz. Bilgisayarlı tomografi (BT) de eski ve yeni kırık ayrımını yapamayacağı için, tanıda altın standart manyetik rezonans (MR) görüntülemedir. MR ile dejeneratif sorunlar, malignite, kırık ve enfeksiyonlar ortaya konulurken eski ve yeni kırık ayrımı da yağ baskılı T2 kesitler kullanılarak kolaylıkla yapılabilir. ${ }^{[2]}$ Bel ağrılı hastada labaratuar tetkileri rutin olarak istenmemekle beraber kırmızı bayrakların varlığında beyaz küre sayımı, eritrosit sedimentasyon hızı (ESR) ve CRP enfeksiyon tanısı için oldukça yardımcıdır. ESR yüksekliği ile birlikte anemi varlığı da malignite tanısını destekler. Malignite tanısında PSA gibi tümör spesifik labaratuar testleri de tanıda büyük önem taşır. ${ }^{[2,16]}$

\section{MAVI BAYRAKLAR}

Literatürde "sarı bayraklar" ilk olarak kas-iskelet sistem kaynaklı uzun dönem sakatlıklarla ilgili olan ve işe dönmeye engel olan psikolojik risk faktörleri olarak tanımlanmıştır. Sarı bayrak kavramı oluşturulurken, sosyal ve çevresel değişkenler gibi diğer risk faktörlerinden etkilenilmemesi için, bu kavram primer olarak psikolojik risk faktörleriyle sınırlandırılmıştır. Kendall ve arkadaşları, ${ }^{[7]}$ psikolojik risk faktörleri olarak "hastanın ağrı veya yaralanma hakkındaki korkuları", "iyileşme hakkındaki yanlış inançları" ve "anksiyete" gibi kavramları tanımlamıştır. Geçtiğimiz yıllarda ise, sarı bayraklar üzerindeki çalışmalar, iş ve işyeriyle ilgili içeriklere yoğunlaşmıştır. Main ve Burton, ${ }^{[17]}$ "sarı bayrak" teriminin sadece korkular ve yanlış inançlar gibi psikolojik risk faktörleri için kullanılması ve sosyal/ çevresel (iş-işyeriyle ilgili) risk faktörlerinin iki kategoriye bölünmesi gerektiğini belirtmişlerdir. Bunlardan birincisi; "işyerinin stresli olduğu”, "işyerindeki çalışma arkadaşları ve amirinin destekleyici olmadığı" ve "işin hastalığı için ağır olduğuna dair kaygıları" içeren "mavi bayraklar", ikincisi ise "siyah bayrak" olarak adlandırılan, işyeri ve işin doğası ile ilgili olan ve iş kazalarının yönetimini içeren sigorta ve tazminat talepleri vb. gibi sistemsel veya özel karakteristiklerdir.

Son zamanlarda, ayrıca, normal olarak kabul edilebilen psikolojik risk faktörleri (bulguların kontrol edilemeyeceği veya kötüleşmeye eğilimli olduğuna inanma vb.) ile tamamen anormal olan psikolojik ve psikiyatrik hastalıkların da ayrımı yapılmıştır. Majör depresyon, posttravmatik stres bozuklukları gibi tanısı konulabilen psikopatolojiler, "turuncu bayrak" olarak ayrı bir sınıfta tanımlanmıştır. ${ }^{[18]}$

Mavi bayraklar ile ilgili çalışmaların incelendiği sistematik analizlerde, çalışanlarda spesifik olmayan bel ağrısı başladıktan sonraki ilk üç hafta içindeki iyileşme ve beklentisinin, işe dönüşün en iyi göstergesi olduğu ortaya konulmuştur. ${ }^{[3,19]}$ Çalışanlarda düşük iyileşme beklentisine bağlı aktivite kısıtlamaları, \%10-100 arasında bulunmuştur.

Literatürde, iş ile ilgili diğer psikolojik faktörlerle ilgili daha çelişkili sonuçlar mevcuttur. Burton ve arkadaşları, ${ }^{[20]}$ yaptıkları sistematik analizde, iş tatminsizliğinin kronik ağrı ve sakatlığın güçlü bir belirleyicisi olduğunu göstermişlerdir. Mcfarlane ve arkadaşlarının ${ }^{[21]}$ altı makaleyi değerlendirdikleri sistematik analizlerinde, iş tatminsizliğinin bel ağrısı ile ilişkili olduğuna dair orta-güçlü kanıt seviyesi bildirilmiştir. 2010'da Chou ve Shekelle, ${ }^{[22]}$ benzer bir şekilde, iş tatminsizliği ne kadar fazla ise kronik sakatlığın ilk bir yılda o kadar fazla olduğunu belirtmişlerdir. Ancak, Hartvigsen ve arkadaşları ${ }^{[23]} 40$ ileriye dönük kohort çalışmayı değerlendirdikleri çalışmalarında, iş tatminsizliği ile bel ağrısı sonuçları arasında bir ilişki kurulamayacağını ve iş yeri stresi ile bel ağrısı sonuçları arasında belirli bir ilişki olmadığına dair orta derecede kanıt olduğunu belirtmişlerdir. Benzer olarak, lles ve arkadaşları ${ }^{[3]} 24$ çalışmadan oluşan sistematik analizlerinde, stres ile bel ağrısı sonuçları arasında belirli bir ilişki olmadığına dair orta derecede kanıt olduğunu belirtmişlerdir. Ancak, birçok çalışmanın da, kişisel stresin bel ağrısı kaynaklı uzun süren sakatlık için belirgin bir risk faktörü olduğunu bildirdiği de akılda tutulmalıdır. ${ }^{[20,24]}$

Mavi bayrak bulgularının hangi anket ile değerlendirileceği ise ayrı bir tartışma konusudur. Gray ve arkadaşları, ${ }^{[25]} 5630$ kişiyi ve sekiz çalışmayı kapsayan sistematik derlemelerinde, altı anketi irdelemiş ve mavi bayrakların değerlendirilebilmesi için bu anketlerden hiçbirini öneremeyeceklerini; yeterli psikometrik özellik gösteren tek anketin, işe geri dönüşteki engeller anketi (Obstacles to Return To Work Questionnaire - ORTWQ) olduğunu; ancak, bunun şu andaki şekliyle klinik olarak kullanışlı olmadığını ve bu konuda daha fazla çalışma yapılması gerektiğini bildirmişlerdir.

\section{ÇIKARIMLAR}

Bel ağrısı olan birçok hasta basit bir tedaviyle düzelmesine rağmen, doğru bir değerlendirme, altta yatan ciddi bir patolojinin ortaya konulabilmesi için çok önemlidir. Bel ağrısı etiyolojisinde nadiren görülen, ancak ciddi sonuçlar doğuran, malignite, travma ve 
enfeksiyona bağlı lezyonların tanısında kırmızı bayrak bulgularının büyük önemi vardır. Literatür, çalışan hastaların işle ilgili algılarının, tedavide başarının ve işe dönüşün önemli bir prognostik göstergesi olduğunu desteklemektedir.

\section{KAYNAKLAR}

1. Airaksinen O, Brox JI, Cedraschi C, Hildebrandt J, KlaberMoffett J, Kovacs F, Mannion AF, Reis S, Staal JB, Ursin $\mathrm{H}$, Zanoli G; COST B13 Working Group on Guidelines for Chronic Low Back Pain. Chapter 4. European guidelines for the management of chronic non-spesific low back pain. Eur Spine J 2006;15 Suppl 2:S192-300.

2. Şenköylü A. Bel ağrısında kırmızı bayraklar. Türk Fiz Tıp Rehab Derg 2011;57 (Kasım):0-0.

3. Iles RA, Davidson M, Taylor NF. Psychosocial predictors of failure to return to work in non-chronic non-spesific low back pain: a systematic review. Occup Environ Med 2008:65(8):507-17. CrossRef

4. Heitz CA, Hilfiker R, Bachmann LM, Joronen H, Lorenz $\mathrm{T}$, Uebelhart D, Klipstein A, Brunner F. Comparison of risk factors predicting return to work between patients with subacute and chronic non-specific low back pain: systematic review. Eur Spine J 2009;18(12):1829-35. CrossRef

5. Staal JB, Hlobil H, van Tulder MW, Waddell G, Burton AK, Koes BW, van Mechelen W. Occupational health guidelines for the management of low back pain: an international comparison. Occup Environ Med 2003;60(9):618-26.

6. Burton AK, Balagué $F$, Cardon G, Eriksen HR, Henrotin Y, Lahad A, Leclerc A, Müller G, van der Beek AJ; COST B13 Working Group on Guidelines for Prevention in Low Back Pain. Chapter 2. European guidelines for prevention in low back pain: November 2004. Eur Spine J 2006;15 Suppl 2:S136-68.

7. Kendall NAS, Linton SJ, Main CJ. Guide to assessing psychosocial yellow flags in acute low back pain: risk factors for long-term disability and work loss. Wellington, New Zealand: Accident Compensation Corporation; 1997.

8. Main CJ, Sullivan MJL, Watson PJ. Pain management: practical applications of the biopsychosocial prespective in clinical and occupational settings. 2nd ed. Edinburgh: Churchill Livingstone; 2008.

9. Shaw WS, van der Windt DA, Main CJ, Loisel P, Linton SJ; "Decade of the Flags" Working Group. Early patient screening and intervention to address individual-level occupational factors ("blue flags") in back disability. J Occup Rehabil 2009;19(1):64-80. CrossRef

10. Turner JA, Franklin G, Fulton-Kehoe D, Sheppard L, Wickizer TM, Wu R, Gluck JV, Egan K. Worker recovery expectations and fear-avoidance predict work disability in a populationbased workers' compensation back pain sample. Spine (Phila Pa 1976) 2006;31(6):682-9.
11. Greenhalgh S, Selfe J. A qualitative investigation of Red Flags for serious spinal pathology. Physiotherapy 2009;95(3):2247. CrossRef

12. Chartered Society of Physiotherapy. Clinical guidelines for the effective physiotherapy management of persistent low back pain. London: CSP; 2007.

13. Roberts L, Fraser F, Murphy EA. What is a Red Flag. 15th International WCPT Congress, Vancouver; 2007.

14. Henschke N, Maher CG, Refshauge KM, Herbert RD, Cumming RG, Bleasel J, YorkJ, Das A, McAuleyJH. Prevalence of and screening for serious spinal pathology in patients presenting to primary care settings with acute low back pain. Arthritis Rheum 2009;60(10):3072-80. CrossRef

15. Casazza BA. Diagnosis and treatment of acute low back pain. American Family Physician 2012;85(4):343-50 .

16. Henschke N, Maher CG, Refshauge KM. Screening for malignancy in low back pain patients: a systematic review. Eur Spine J 2007;16(10):1673-9.

17. Main CJ, Burton AK. Economic and occupational influences on pain and disability. In: Main CJ, Spasnswick, editors. Pain Management: An interdisciplinary approach. Edinburg, Scotland: Churchill Livingstone; 2000. p.63-87.

18. Nicholas MK, Linton SJ, Watson PJ, Main CJ; "Decade of the Flags" Working Group. Early identification and management of psychological risk factors ("yellow flags") in patients with low back pain: a reappraisal. Phys Ther 2011;91(5):737-53. CrossRef

19. Fadyl J, McPherson K. Return to work after injury: a review of evidence regarding expectations and injury perceptions, and their influence on outcome. J Occup Rehabil 2008;18(4):36274. CrossRef

20. Burton AK, Waddell G, Bartys S, Main CJ. Screening to identify people at risk of long term incapacity: a conceptual and scientific review. Disability Medicine 2003:3(3):72-83.

21. Macfarlane GJ, Pallewatte N, Paudyal P, Blyth FM, Coggon D, Crombez G, Linton S, Leino-Arjas P, Silman AJ, Smeets RJ, van der Windt D. Evaluation of work-related psychosocial factors and regional musculoskeletal pain: results from a EULAR Task Force. Ann Rheum Dis 2009;68(6):885-91. CrossRef

22. Chou R, Shekelle P. Will this patient develop persistent disabling low back pain? JAMA 2010;303(13):1295-302. CrossRef

23. Hartvigsen J, Lings S, Leboeuf-Yde C, Bakketeig L. Psychosocial factors at work in relation to low back pain and consequences of low back pain; a systematic, critical review of prospective cohort studies. Occup Environ Med 2004;61(1):e2.

24. Shaw WS, Pransky G, Fitzgerald TE. Early prognosis for low back disability: intervention strategies for health care providers. Disabil Rehabil 2001;23(18):815-28.

25. Gray $\mathrm{H}$, Adefolarin AT, Howe TE. A systematic review of instruments for the assessment of work-related psychosocial factors (Blue Flags) in individuals with non-specific low back pain. Man Ther 2011;16(6):531-43. CrossRef 